\title{
The challenges for molecular nutrition research 2: quantification of the nutritional phenotype
}

\author{
Ben van Ommen · Jaap Keijer · Robert Kleemann • \\ Ruan Elliott · Christian A. Drevon · Harry McArdle • \\ Mike Gibney $\cdot$ Michael Müller
}

Received: 12 April 2008/Accepted: 26 May 2008/Published online: 25 June 2008

(C) The Author(s) 2008

\begin{abstract}
In quantifying the beneficial effect of dietary interventions in healthy subjects, nutrition research meets a number of new challenges. Inter individual variation in biomarker values often is larger than the effect related to the intervention. Healthy subjects have a remarkable capacity to maintain homeostasis, both through direct metabolic regulation, metabolic compensation of altered diets, and effective defence and repair mechanisms in oxidative and inflammatory stress. Processes involved in these regulatory activities essentially different from processes involved in early onset of diet related diseases. So, new concepts and approaches are needed to better quantify the subtle effects possibly achieved by dietary interventions in healthy
\end{abstract}

All authors are members of The European Nutrigenomics Organisation (http://www.nugo.org). MM and $\mathrm{BvO}$ are members of the Dutch

Nutrigenomics Consortium (http://www.nutrigenomicsconsortium.nl).

B. van Ommen $(\bowtie) \cdot$ R. Kleemann

Department of BioSciences, TNO-Quality of Life,

Zeist, The Netherlands

e-mail: ben.vanommen@tno.nl

R. Kleemann

e-mail: robert.kleemann@tno.nl

J. Keijer

RIKILT-Institute of Food Safety and Wageningen University,

Wageningen, The Netherlands

e-mail: jaap.keijer@wur.nl

R. Elliott

Institute of Food Research, Norwich Research Park,

Colney, Norwich NR4 7UA, UK

C. A. Drevon

Department of Nutrition, Institute of Basic Medical Sciences,

Faculty of Medicine, University of Oslo, POB 1046,

Blindern, 0316 Oslo, Norway

e-mail: c.a.drevon@medisin.uio.no subjects. Apart from quantification of the genotype and food intake (these are discussed in separate reviews in this series), four major areas of innovation are discussed: the biomarker profile concept, perturbation of homeostasis combined with omics analysis, imaging, modelling and fluxes. All of these areas contribute to a better understanding and quantification of the nutritional phenotype.

Keywords Nutritional phenotype - Homeostasis ·

Perturbation $\cdot$ Imaging

\section{Health status quantification}

Nutrition research is focused on the impact of foods on health. Traditionally, biomarkers related to (the onset of) disease or organ damage were used to quantify the effects. With the emerging drive to focus on the exploitation of food

H. McArdle

Rowett Research Institute, Aberdeen, UK

e-mail: h.mcardle@rowett.ac.uk

M. Gibney

UCD Institute of Food and Health, University College Dublin,

Dublin, Ireland

e-mail: mike.gibney@ucd.ie

M. Müller

Division of Human Nutrition, Nutrition, Metabolism and Genomics group, Wageningen University, Bomenweg 2, 6703 HD Wageningen, The Netherlands

e-mail: michael.muller@wur.nl 
for health optimization and disease prevention, it becomes necessary to quantify phenotypic changes which are very close to, or even within the range of the healthy state. This imposes major challenges, because diet-induced changes in phenotype usually are very small and hard to quantify and the system rapidly re-establishes normal homeostasis. Moreover, these changes usually are smaller than the interindividual variations within a healthy phenotype [21, 62]. Thus, accurate quantification of the effect of nutrients on health is a major bottleneck for progress. This is true for genetically defined sub-groups as well as for nutrition research in general. The research area of nutrigenomics has made enormous progress in recent years, applying omics technologies in the diet-health relationship [10, 19, 34, 52]. Yet, this has primarily focused on unravelling mechanisms and biomarker profiles. The aim of this review is to consider the different aspects of ' quantification of health effects and provide specific recommendations. The term 'nutritional phenotype' has been introduced with this purpose in mind [72], and is defined as a set of integrated genetic, transcriptomic, proteomic, metabolomic, functional and behavioral data, which provide the basis for assessment of human nutritional status and health. In a limited number of cases the phenotype is strongly and straightforwardly correlated to genotype (e.g. phenylalanine ketonuria), but the nutritiongenotype-phenotype relation is relevant even in cases where no straight forward translation from genotype to phenotype is possible [11]. Recent emerging knowledge on the epigenetic variation of this genotype-phenotype relationship allows a more precise understanding of the plasticity of our phenotype and the impact of nutrition on this.

Complex and subtly regulated processes such as glucose homeostasis are full of genotypic differences. Nevertheless, homeostasis is maintained by 'individual' adaptation of a multitude of nutritionally regulated processes [15]. Daily dietary intake influences nutritional status through, for example, the postprandial response to lipids, proteins or carbohydrates [31, 43] and nutritional phenotype stems from lifetime's exposure, beginning with fetal life [5, 42, 64] and stretching into old age [2]. There are marked changes as an individual goes through life, which emphasize their own peculiar and individual adjustments. Certain phenotypic aspects change continuously while others progress more gradually, leading to modification of health status. Development of disease phenotypes thus reflects interaction between a 'sensitive genotype' and nutrient-derived metabolic stressors, which influence a multitude of molecular mechanisms.

\section{Bottlenecks}

In addition to the genetic variation as discussed in the first review of this series [67] and inaccurate food intake

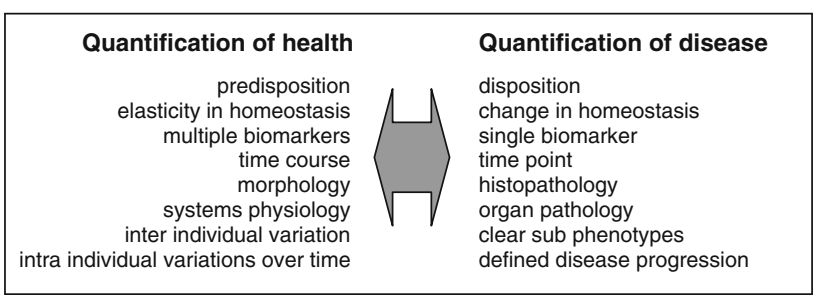

Fig. 1 Differences between quantification of health and quantification of disease. Although the change from health to disease can be seen as a continuum, and thus the above discriminations should not be regarded absolute, each of the indicated differences describes both the difficulties encountered in quantification of health as well as the opportunities for research direction

assessment, there are a variety of issues interfering with the quantification of the subtle health effects related to diet including (also see Fig. 1):

- Intra- and inter-individual variation caused by confounding' factors, which mask significant change.

- Absence of appropriate biomarkers for quantification of early changes.

- Difficulty in discriminating between temporary and lasting health effects.

- Metabolic compensations for nutritional alterations.

\section{Approaches}

Four new approaches have emerged, which are worth further development. These are described below, and presented in Fig. 2.

\section{Biomarkers profile concept}

Many of the established traditional risk markers or biomarkers such as LDL-cholesterol, HDL-cholesterol, triglycerides, glucose, homocysteine, IL-6, fibrinogen,

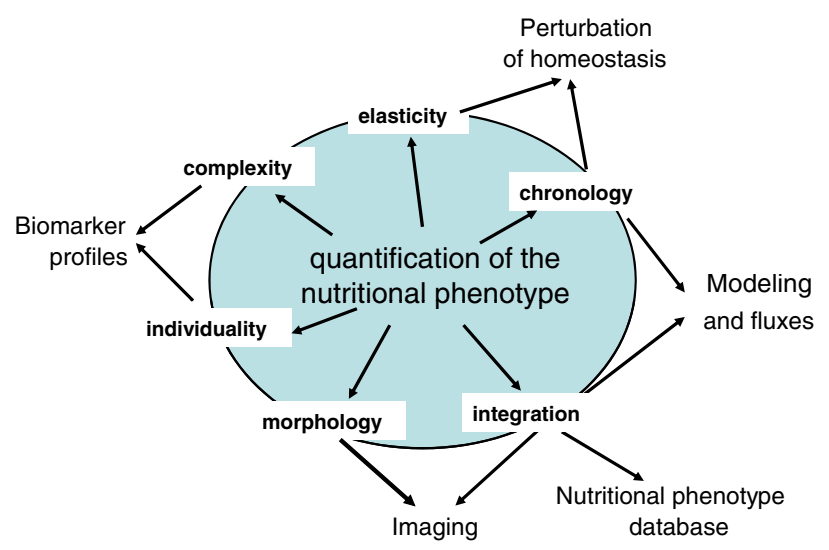

Fig. 2 Some of the unique features of quantification of the nutritional phenotype, as described above and presented in Fig. 1, are related to the approaches presented in this paper 
serum amyloid A (SAA) and C-reactive protein (CRP) were identified by classical epidemiology and their value to predict future disease or future pathological events was confirmed in large prospective cohorts [18, 26, 49]. Some of these markers (e.g. LDL cholesterol or glucose) are not only risk markers but can participate as risk factors in the molecular processes that drive the disease development they predict [30]. Such a clear pathological role has only been established for a few of the risk markers that traditionally are used in the fields of medicine and nutrition. For example, IL- 6 can promote and retard the process of atherosclerosis [28, 40, 56], and an active role of CRP, a strong independent marker of future cardiovascular events, is discussed controversially [48]. It is likely that the high predictive power and the sensitivity of markers such as CRP stems from their ability to integrate several risk factors with a relatively short half life in plasma (i.e. IL-1, IL-6 and TNF $\alpha$ in the case of CRP). [33, 47]. An important drawback of those biomarkers that cannot be mechanistically linked to a specific disease process is that they often are not suitable for assessing or predicting individual outcome, only that of a population. On the other hand, a drawback of the biomarkers that actively participate in the disease process is that they have only a limited use in predicting an early stage of a disease: once they are found to be elevated, the disease process has already begun and it is often too late for a (mild) intervention, for example by nutritional adjustments. Therefore, and in particular for nutritional interventions, novel biomarkers are necessary; (a) that can be used to monitor the individual health status, and (b) that sense future risk at a very early time point.

The recent developments in systems biology enable us to accurately determine many metabolites, lipids and proteins in plasma [63]. This technological improvement in combination with multivariate data analysis [57] provides new opportunities to generate more comprehensive and complete 'biomarker profiles' which allow us to better define the individual health status, and to discriminate it from a status that is associated with health risk [34]. Indeed recent systems biology studies demonstrate that metabolomic profiles (even at baseline) can capture characteristics of early onset of disease, and may represent useful tools to monitor nutritional intervention [37, 38]. Better assessment of the phenotype of an individual will enable us to fine-tune the classification of individuals, a topic of great relevance to optimize nutritional as well as medical interventions. The coming years will reveal whether multivariate biomarker profiles, e.g. plasma fingerprints obtained by measuring a multitude of parameters followed by sophisticated statistical analyses, are more powerful in detecting early changes than the limited set of traditional individual biomarkers that is used traditionally.
Biomarker profiles can be determined at the level of metabolites including lipids, i.e. by applying powerful state-of-the-art and standardized metabolomics and lipidomics which require only a few microliters of plasma $(<5 \mu \mathrm{l})$ or at the proteome or transcriptome level technologies $[23,37,38,44,54,72]$. For example, the use of peripheral blood mononuclear cells (PBMC) for genomewide gene expression analysis to identify biomarkers in human intervention studies is currently being explored and new omics-based biomarker sets appear to provide more sensitive diagnostic tools for describing the nutritional phenotype $[9,20,21,62]$. This will enable us to discriminate between healthy and unhealthy phenotypes more effectively than classical approaches [1, 45]. Further development of these novel tools and refinement of the omics tools for the nutrigenomics research field will provide us with the opportunity to describe the more subtle effects of the nutritional phenotype more accurately and comprehensively along the line of recent biomarker profiling concepts $[8,35,54]$.

\section{Perturbation of homeostasis}

Maintaining homeostasis in a timely manner is essential for optimal health. Early signs of homeostatic disturbance as observed in onset of disease may be detected using the biomarker profile approach described above, but in describing nutritional effects on a healthy phenotype, the very fact that we try to describe homeostasis limits the power of this approach. To overcome these limits, challenge tests are introduced in nutrition and health research [22]. These include variations of oral glucose and lipid tolerance tests [68] organ function tests or exercise challenge [25]. Two important aspects addressed by challenge tests are:

- Nutrition-related disorders often arise from repeated dietary challenges. For example, insulin resistance arises from repeated metabolic challenges with oxidative stress [14]. Understanding the molecular physiology of dietary challenges, specifically compensatory, regulatory and damage-control mechanisms, in terms of oxidative and inflammatory responses, might lead to personalized enhancement or adaptation of nutritional patterns.

- Challenging a system reveals weaknesses in metabolic flexibility and robustness. Glucose tolerance tests, or other functional tests, may provide more information on metabolic status than static measurements (e.g. fasting glucose).

Multiple regulatory systems are challenged simultaneously during dietary exposures, and do not react independently. Thus, an integrated approach in quantification of both the challenge and the response are needed. 
Omics technologies aid acquisition and processing of such data.

Combining omics-based biomarkers with homeostatic challenges may offer a second generation of omics-derived early biomarkers of disease. Regardless, the multiple measurements will provide detailed descriptions of the challenge responses, enabling different aspects to be explored. For example, pro- and anti-inflammatory response to a metabolic challenge can be quantified based on the level of classical measures such as C-reactive protein and interleukins but also the time course of some 100 plasma proteins, which can be quantified using multiplex approaches, targeted metabolomics [70] or transcriptomics like analysis of the complete leukocyte inflammation interactome [12]. This will require dealing with small signals (i.e. healthy response), intermediate signals (i.e. pre-disease/sub-clinical conditions) and strong signals (i.e. disease at different stages). Complex biomarkers that take advantage of areaunder-the-curve measurements of organ responses to specific challenges may provide tools for more sensitive diagnostic nutritional phenotyping required for disease prevention and dietary and lifestyle intervention.

Currently, there are significant limitations regarding the commonly monitored parameters, used for assessment in healthy people. For example, how can we measure noninvasively the contribution of internal organs such as liver, pancreas, visceral fat or small intestine and their contribution to the nutritional phenotype? Mechanistic studies in animal models will lead to markers, which offer organspecific nutritional phenotypic information (e.g. liver-specific protein secreted after a fatty acid challenge) or similar diet-induced parameters.

Several options are available to enhance the resolution of the nutritional assessment. One option is to increase the power by using larger groups, but this is often difficult especially in the initial stage of challenge approaches. As an alternative it may be attractive to preselect a homogenous (sub)group for the identification of effects and responses and from there proceed to a larger population, using less complicated and more focussed assessment procedures. Another option is to intensify efforts in phenotyping. One example is the use of non-invasive imaging (TD-NMR, see also next paragraph) in animal studies to quantify the amount lean mass over fat mass, which provides information over time, rather than establishing this only at the moment of sacrifice of the animal [58]. Intensifying phenotyping has two major advantages. First, it increases the efficiency of establishing the relationship between molecular change and phenotype. Second, it reduces the amount of experimental animals and humans. Phenotyping can be done by including behavioural assessments in nutrition feeding studies. Behavioural aspects that can be studied in animals include learning and memory using maze systems and avoidance conditioning, motor function using grip strength, rota rods and neurosensory performance using acoustic and tactile startle responses. As an example, dietary resveratrol was shown to induce molecular changes leading to improved mitochondrial function, which was supported by enhanced mitochondrial density and functional assessment of mitochondrial respiration [41]. However, the relevance of the findings came from associated phenotyping, in particular from an endurance test showing improved fitness [36].

Automation is an important aspect of phenotyping. Passive transponders can be implanted in animals for constant monitoring of temperature thus revealing small, but significant differences in body temperature which would otherwise remain unnoticed [29, 32]. Similarly, feeding, drinking and movement can be monitored automatically not only providing more accurate data, but also giving information on periodicity. Presently, setups are available for combined eating, drinking, $x-y-z$ movement, activity (e.g. running wheel), and calorimetric measurements (e.g. http://www.colinst.com or http://www.TSE-systems.com). The inclusion of this in nutritional studies will be a further step towards characterization of the healthy phenotype. While the above is detailed and exemplified for animals studies, the same is obviously also relevant for human studies, which would benefit from intensified phenotyping in parallel to challenge studies and omic assessments.

\section{Imaging}

In addition to classical phenotypic descriptors in nutrition, whole body imaging methods are essential; i.e. non-invasive methods to assess the nutritional phenotype online during challenge studies. These will support omics-driven nutritional phenotyping with functional physiological area under the curve (AUC) data sets. Nutrition research has always been hampered by the inability to undertake detailed analyses in vivo. Imaging offers a very powerful tool, which allows real-time analysis in vivo, and new noninvasive diagnostic concepts will develop into applications that can subsequently be applied in medical diagnostics (Table 1).

The already extensively applied X-ray technology has been extremely helpful in detecting differences in tissue densities like in bones. Computed tomography (CT) represents an advanced development of imaging based on a large series of two-dimensional X-rays taken around a single axis of rotation (tomos is Greek = slice) often combined with injections of contrast agents of different types. The images are digitally processed to create threedimensional images. Although X-rays can be used in relation to nutritional questions this technology is often not sensitive enough for most metabolic questions. 
Table 1 Imaging techniques of interest in nutritional research

\begin{tabular}{|c|c|c|c|}
\hline Type & Abbreviation & Principle & Application \\
\hline Röntgen array & X-ray & $\begin{array}{l}\text { Different absorption of ionizing } \\
\text { radiation based on tissue density }\end{array}$ & $\begin{array}{l}\text { Skeletal and dense inner } \\
\text { organs }\end{array}$ \\
\hline Computed tomography & CT or CAT scan & $\begin{array}{l}\text { Focused X-ray pictures in several } \\
\text { "slices" computerized to 3D } \\
\text { images }\end{array}$ & $\begin{array}{l}\text { Accurate imaging of organs } \\
\text { and tissues }\end{array}$ \\
\hline Positron emission tomography & PET & $\begin{array}{l}\text { Injected radio-tracers are detected } \\
\text { as gamma emitters }\end{array}$ & $\begin{array}{l}\text { Detect blood flow, } \\
\text { metabolic changes }\end{array}$ \\
\hline Magnetic resonance & MR & $\begin{array}{l}\text { Charged molecules are realigned } \\
\text { in a strong and oscillating } \\
\text { magnetic field with different } \\
\text { rates }\end{array}$ & $\begin{array}{l}\text { Soft tissues like adipose, } \\
\text { muscle, heart, joints can } \\
\text { be accurately quantified }\end{array}$ \\
\hline Magnetic ressonance spectroscopy & MRS & $\begin{array}{l}\text { MR combined with spectroscopy } \\
\text { of protons, phosphorus, sodium, } \\
\text { etc. }\end{array}$ & $\begin{array}{l}\text { Linked to expression and } \\
\text { regulation of transgenes }\end{array}$ \\
\hline Bioluminscence & - & $\begin{array}{l}\text { Luciferase promotes light emission } \\
\text { upon activation }\end{array}$ & $\begin{array}{l}\text { Detection of inflammatory } \\
\text { response caused by } \\
\text { supply of nutrients }\end{array}$ \\
\hline
\end{tabular}

Molecular imaging enables the visual representation, characterization, and quantification of biological processes at the cellular and subcellular levels within intact living organisms [34, 41]. This approach offers distinct advantages compared to more invasive methods. For example, molecular imaging allows the visualization of the temporal as well as the spatial regulation of a specific gene in a realistic manner, keeping the dynamics of complex biological networks in an intact organism. Non-invasive imaging also provides the possibility of repetitive assessments in the same individual allowing the individual to serve as its own control. Contag et al. [16] demonstrated for the first time that bioluminescence from luciferase encoded by the bacterial luciferase gene could be detected in living mice. In their study of mice infected with recombinant bacteria containing the luciferase gene, the luminescence within the mice was strong enough to be detected using an external light-sensitive camera. It has subsequently been shown that transgenic reporter mice with luciferase from firefly was readily assessed non-invasively [17]. Blomhoff et al. have successfully used this luciferase imaging technique in nutrional studies related to inflammation orchestrated via the essential transcription factor NF- $\kappa \mathrm{B}[6,13]$. There are now several other detection methods to image gene expression in addition to luciferase-mediated imaging.

The most promising of the new technologies are positron emission tomography (PET) [24], magnetic resonance imaging (MRI) [65] and optical imaging using green fluorescent protein [69] or near infra red fluorescence ([66] which have been used to image in vivo gene regulation.

MRI spectroscopy (MRS) equipment can be tuned register signals from nuclei like protons $(\mathrm{H}+)$, phosphorus, sodium and fluorine. allows detection and assessment of transfer, expression and subsequent intervention changes of effectors or marker transgenes noninvasively in vivo [7]. "Smart" MR contrast agents have been developed, making it possible to change their conformational structure and thereby induce MR-detectable changes. These agents are "activated" in response to physiological changes promoted by biological reactions in cells, isolated organs and whole animals. Similarly, MR spectroscopy is also used as a noninvasive method to assess transgene expression indirectly by means of MR-visible intracellular markers. These markers take the form of intracellular endo/exogenous metabolites associated with exogenous enzyme expression and function. This technique is also applicable to many different situations, from isolated cells to clinical imaging of the whole body.

Positron emission tomography scanning is based on use of positron emitting radioisotope (tracer), given into the body on a biologically active molecule. The positron is also called anti-electron and is the antiparticle of the electron. The positron has a positive electrical charge with the same mass as an electron. When a low-energy positron collides with a low-energy electron, annihilation occurs, resulting in the production of two gamma ray photons. 2-fluoro-2deoxy-D-glucose (abbreviated FDG) is a glucose derivative with fluorine $18\left({ }^{18} \mathrm{~F}\right)$ is often used as isotope generating gamma arrays. This isotope emits very small and only temporary radioactivity and is used for describing uptake and phosphorylation of glucose in different tissues. Images of tracer concentration in 3-dimensional space are reconstructed by data analysis. In modern scanners, this reconstruction is often obtained by the aid of a CT X-ray or MRI scanning performed on the subject during the same PET session, in the same machine. Also other tracers than FDG are used in PET scanning to image the tissue concentration or metabolism, like oxygen- 15 . 
The MRI provides much greater soft tissue contrast than CT. Unlike CT it uses no ionizing radiation, but a strong magnetic field to align the nuclear magnetization of charged molecules in the body. Radiofrequency fields are used to alter the alignment of this magnetization, causing the hydrogen nuclei (most often used) to produce a rotating magnetic field detectable by the scanner. This signal can be manipulated by additional magnetic fields to build up enough information to reconstruct a 3D image. MRI may be combined with angiography and CT $\mathrm{X}$-ray.

The MRI has been further developed including conjugates consisting of gene-targeting short nucleic acids (oligodeoxynucleotides, or sODN) and superparamagnetic iron oxide nanoparticles (SPION, and MR susceptibility T2 agent) for reporting gene activity using transcription MRI (tMRI; [39]). This method has been validated by the correlations between results from conventional assays (in situ hybridization, PCR, histology Prussian blue stain and immunohistochemistry) in postmortem samples, and retention of SPION-sODN using tMRI. Due to the recognition of nucleic acid sequences, tMRI probes with complementary nucleic acid (antisense DNA or short interfering RNA) allows tracking, targeting, binding to intracellular mRNA, and manipulating gene action, in addition to tracing cells with specific gene action in living tissues. Transcription MRI may most likely be used for many applications in living organs also related to nutrition.

\section{Modelling and fluxes}

In quantifying health, the dynamic and kinetic aspects should also be incorporated. This is partly addressed by challenge tests (e.g. glucose or fat kinetics), but it can be extended in many ways. For example, in vivo de novo lipogenesis quantification by deuterated water flux analysis [59] and lipoprotein biosynthesis and half-life by deuterated leucine [1], both indicate how in vivo kinetics may provide extra information in quantifying phenotypic effects of nutrients.

Absorption patterns for micronutrients such as iron [55] have been studied extensively using stable isotopes. In essence, these data have been used to develop models of absorption and of distribution within the organism. Some studies have been carried out in different physiological conditions (e.g. pregnancy) but they are difficult to set up and analyse and interpretation is fraught with complications. A mathematical approach is currently being developed and has been applied to other micronutrients such as folate $[46,60]$. These topics are further addressed in review 4 in this series (systems biology approaches in nutrition).

\section{Towards a practical nutritional phenotype description}

Many of the options described above are in the early stages of development, and a major effort will be required before we can hope to draw on meaningful omics-derived conclusions. As a priority, we need to understand homeostasis not only in terms of relevant nutrigenomics data but also to distinguish significant health markers from the background noise, i.e. changes in gene expression, protein translation and functionality, and metabolite concentrations. Early agreement on a minimum set of parameters to be measured in the majority of human nutritional studies would ease comparison of results and establishment of a depository of data for sharing. This requires extensive consensus as well as provision of secure information systems.

One of the first steps towards this goal is to develop systems that can capture accurately subtle changes in a multitude of biological variables. This poses a substantial challenge that requires standardized technology, methodology and data formats. Many lessons can be learned from the mouse phenotyping community $[3,4,27]$. NuGO (http://www.nugo.org) is currently building a set of online tools, which could form the basis of nutritional phenotype quantification, with the option to select, standardize, store and query the relevant parameters. These elements are now all centred around "NutriBASE", a laboratory information management system (LIMS), which captures nutritional studies with a strong omics component. NutriBase incorporates structured storage of nutritional metadata (i.e. study design, treatments, phenotypic observations, etc.), enabling subsequent detailed querying of datasets in databases. Within the same database, transcriptomics (raw) data and results can be stored and traced. NutriBASE is an extension of BASE 2, an open source transcriptomics LIMS [51]. NutriBASE follows all current standards and exports to public databases like ArrayExpress [50].

The NuGO developers and other collaborators are currently trying to extend this system to enable capture and enhanced querying of all types of information, including dietary intake, metabolomic and proteomic, (epi)genetic and in vivo imaging data, with the ultimate goal of developing a nutritional phenotype database. It is envisaged that a modular architecture will be employed for the different components (study design and different data sets) as this not only represents an efficient manner to store data but also provides the flexibility to add extra modules to accommodate new technologies and all types of nutrition and health research studies. The development will be carefully aligned with other ongoing activities spanning different biological sciences such as the EU Framework 7 Programme project ELIXIR, which is coordinating the development of a new European Life Sciences Infrastructure For Biological Information (see http://www.elixir-europe.org). This is to 
avoid unnecessary replication and move more rapidly towards universal standards.

Finally, of critical importance in the development of nutritional phenotype databases is the need to develop methods which integrate the biological and imaging data with estimates of food and nutrient intake. At present, the latter are hampered by the phenomenon of under-reporting of food and nutrient intake and in this respect metabolomics may have a role, not in the definitive analysis of the diets of individuals but in allocating individuals to one of a number of highly characterized metabolomic profiles. A second area which will need attention to integrate omics with dietary data will be the capacity to characterize dietary patterns over a given time period in toto, rather than the present system of the average intakes of individual foods or individual nutrients. Radical new thinking in the collection, analysis and presentation of dietary data is an imperative in this area. This will be the topic of review nr 5 in this series.

Open Access This article is distributed under the terms of the Creative Commons Attribution Noncommercial License which permits any noncommercial use, distribution, and reproduction in any medium, provided the original author(s) and source are credited.

\section{References}

1. Adiels M, Taskinen MR, Packard C, Caslake MJ, Soro-Paavonen A, Westerbacka J, Vehkavaara S, Hakkinen A, Olofsson SO, YkiJarvinen H, Boren J (2006) Overproduction of large VLDL particles is driven by increased liver fat content in man. Diabetologia 49:755-765

2. Arai Y, Hirose N (2004) Aging and HDL metabolism in elderly people more than 100 years old. J Atheroscler Thromb 11:246252

3. Argmann CA, Chambon P, Auwerx J (2005) Mouse phenogenomics: the fast track to "systems metabolism. Cell Metab 2:349-360

4. Argmann CA, Champy MF, Auwerx J (2006) Evaluation of energy homeostasis, chap 29. Curr Protoc Mol Biol

5. Armitage JA, Poston L, Taylor PD (2008) Developmental origins of obesity and the metabolic syndrome: the role of maternal obesity. Front Horm Res 36:73-84

6. Austenaa LM, Carlsen H, Ertesvag A, Alexander G, Blomhoff HK, Blomhoff R (2004) Vitamin A status significantly alters nuclear factor-kappaB activity assessed by in vivo imaging. FASEB J 18:1255-1257

7. Bell JD, Taylor-Robinson SD (2000) Assessing gene expression in vivo: magnetic resonance imaging and spectroscopy. Gene Ther 7:1259-1264

8. Bollard ME, Stanley EG, Lindon JC, Nicholson JK, Holmes E (2005) NMR-based metabonomic approaches for evaluating physiological influences on biofluid composition. NMR Biomed $18: 143-162$

9. Bouwens M, Afman LA, Muller M (2007) Fasting induces changes in peripheral blood mononuclear cell gene expression profiles related to increases in fatty acid beta-oxidation: functional role of peroxisome proliferator activated receptor alpha in human peripheral blood mononuclear cells. Am J Clin Nutr $86: 1515-1523$
10. Bunger M, Hooiveld GJ, Kersten S, Muller M (2007) Exploration of PPAR functions by microarray technology-a paradigm for nutrigenomics 7. Biochim Biophys Acta 1771:1046-1064

11. Caldwell J (2004) Pharmacogenetics and individual variation in the range of amino acid adequacy: the biological aspects. J Nutr 134:1600S-1604S

12. Calvano S, Xiao W, Richards D, Felciano R, Baker H, Cho R, Chen R, Brownstein B, Cobb JP, Tschoeke SK, Miller-Graziano C, Moldawer L, Mindrinos M, Davis R, Tompkins R, Lowry S, LSCRPaHRt Injury (2005) A network-based analysis of systemic inflammation in humans. Nature 437:1032-1037

13. Carlsen H, Alexander G, Austenaa LM, Ebihara K, Blomhoff R (2004) Molecular imaging of the transcription factor NF-kappaB, a primary regulator of stress response. Mutat Res 551:199-211

14. Choi SW, Benzie IFF, Ma SW, Strain JJ, Hannigan BM (2008) Acute hyperglycemia and oxidative stress: Direct cause and effect? Free Rad Biol Med 44:1217-1231

15. Collier JJ, Scott DK (2004) Sweet changes: glucose homeostasis can be altered by manipulating genes controlling hepatic glucose metabolism. Mol Endocrinol 18:1051-1063

16. Contag CH, Contag PR, Mullins JI, Spilman SD, Stevenson DK, Benaron DA (1995) Photonic detection of bacterial pathogens in living hosts 17. Mol Microbiol 18:593-603

17. Contag PR, Olomu IN, Stevenson DK, Contag CH (1998) Bioluminescent indicators in living mammals. Nat Med 4:245-247

18. Criqui MH (1986) Epidemiology of atherosclerosis: an updated overview. Am J Cardiol 57:18C-23C

19. de Wilde J, Mohren R, van den BS, Boekschoten M, Dijk KW, de GP, Muller M, Mariman E, Smit E (2008) Short-term high fat-feeding results in morphological and metabolic adaptations in the skeletal muscle of C57BL/6 J mice. Physiol Genom 32:360-369

20. Debey S, Zander T, Brors B, Popov A, Eils R, Schultze JL (2006) A highly standardized, robust, and cost-effective method for genome-wide transcriptome analysis of peripheral blood applicable to large-scale clinical trials. Genomics 87:653-664

21. Eady JJ, Wortley GM, Wormstone YM, Hughes JC, Astley SB, Foxall RJ, Doleman JF, Elliott RM (2005) Variation in gene expression profiles of peripheral blood mononuclear cells from healthy volunteers. Physiol Genom 22:402-411

22. Elliott R, Pico C, Dommels Y, Wybranska I, Hesketh J, Keijer J (2007) Nutrigenomic approaches for benefit-risk analysis of foods and food components: defining markers of health. Br J Nutr 98:1095-1100

23. Fiehn O, Kristal B, van OB, Sumner LW, Sansone SA, Taylor C, Hardy N, Kaddurah-Daouk R (2006) Establishing reporting standards for metabolomic and metabonomic studies: a call for participation. OMICS 10:158-163

24. Gambhir SS, Barrio JR, Phelps ME, Iyer M, Namavari M, Satyamurthy N, Wu L, Green LA, Bauer E, MacLaren DC, Nguyen K, Berk AJ, Cherry SR, Herschman HR (1999) Imaging adenoviral-directed reporter gene expression in living animals with positron emission tomography. Proc Natl Acad Sci USA 96:2333-2338

25. Graham TE, Helge JW, MacLean DA, Kiens B, Richter EA (2000) Caffeine ingestion does not alter carbohydrate or fat metabolism in human skeletal muscle during exercise. J Physiol 529(Pt 3):837-847

26. Haverkate F, Thompson SG, Pyke SD, Gallimore JR, Pepys MB (1997) Production of C-reactive protein and risk of coronary events in stable and unstable angina. European concerted action on thrombosis and disabilities angina pectoris study group. Lancet 349:462-466

27. Heikkinen S, Argmann CA, Champy MF, Auwerx J (2007) Evaluation of glucose homeostasis, chap 29: Unit. Curr Protoc Mol Biol 
28. Huber SA, Sakkinen P, Conze D, Hardin N, Tracy R (1999) Interleukin-6 exacerbates early atherosclerosis in mice. Arterioscler Thromb Vasc Biol 19:2364-2367

29. Jurgens HS, Schurmann A, Kluge R, Ortmann S, Klaus S, Joost HG, Tschop MH (2006) Hyperphagia, lower body temperature, and reduced running wheel activity precede development of morbid obesity in New Zealand obese mice. Physiol Genom 25:234-241

30. Kannel WB (2005) Overview of hemostatic factors involved in atherosclerotic cardiovascular disease. Lipids 40:1215-1220

31. King IB, Lemaitre RN, Kestin M (2006) Effect of a low-fat diet on fatty acid composition in red cells, plasma phospholipids, and cholesterol esters: investigation of a biomarker of total fat intake. Am J Clin Nutr 83:227-236

32. Klaus S, Munzberg H, Truloff C, Heldmaier G (1998) Physiology of transgenic mice with brown fat ablation: obesity is due to lowered body temperature. Am J Physiol 274:R287-R293

33. Kleemann R, Gervois PP, Verschuren L, Staels B, Princen HM, Kooistra T (2003) Fibrates down-regulate IL-1-stimulated Creactive protein gene expression in hepatocytes by reducing nuclear p50-NFkappa B-C/EBP-beta complex formation. Blood 101:545-551

34. Kleemann R, Verschuren L, van Erk MJ, Nikolsky Y, Cnubben NH, Verheij ER, Smilde AK, Hendriks HF, Zadelaar S, Smith GJ, Kaznacheev V, Nikolskaya T, Melnikov A, Hurt-Camejo E, van der GJ, van OB, Kooistra T (2007) Atherosclerosis and liver inflammation induced by increased dietary cholesterol intake: a combined transcriptomics and metabolomics analysis. Genome Biol 8:R200

35. Kussmann M, Fdr Raymond, Affolter M (2006) OMICS-driven biomarker discovery in nutrition and health. J Biotechnol 124:758-787

36. Lagouge M, Argmann C, Gerhart-Hines Z, Meziane H, Lerin C, Daussin F, Messadeq N, Milne J, Lambert P, Elliott P, Geny B, Laakso M, Puigserver P, Auwerx J (2006) Resveratrol improves mitochondrial function and protects against metabolic disease by activating SIRT1 and PGC-1alpha. Cell 127:1109-1122

37. Lamers RJAN, van Nesselrooij JHJ, Kraus VB, Jordan JM, Renner JB, Dragomir AD, Luta G, van der Greef J, DeGroot J (2005) Identification of an urinary metabolite profile associated with osteoarthritis. Osteoarthritis Cartil 13:762-768

38. Lamers RJ, DeGroot J, Spies-Faber EJ, Jellema RH, Kraus VB, Verzijl N, TeKoppele JM, Spijksma GK, Vogels JTWE, van der Greef J, van Nesselrooij JHJ (2003) Identification of disease- and nutrient-related metabolic fingerprints in osteoarthritic Guinea pigs. J Nutr 133:1776-1780

39. Liu PK, Mandeville JB, Dai G, Jenkins BG, Kim YR, Liu CH (2007) Transcription MRI: a new view of the living brain. Neuroscientist

40. Madan M, Bishayi B, Hoge M, Amar S (2008) Atheroprotective role of interleukin- 6 in diet- and/or pathogen-associated atherosclerosis using an ApoE heterozygote murine model. Atherosclerosis 197:504-514

41. Massoud TF, Gambhir SS (2003) Molecular imaging in living subjects: seeing fundamental biological processes in a new light. Genes Dev 17:545-580

42. McMillen IC, Robinson JS (2005) Developmental origins of the metabolic syndrome: prediction, plasticity, and programming. Physiol Rev 85:571-633

43. Noguchi Y, Zhang QW, Sugimoto T, Furuhata Y, Sakai R, Mori M, Takahashi M, Kimura T (2006) Network analysis of plasma and tissue amino acids and the generation of an amino index for potential diagnostic use. Am J Clin Nutr 83:513S-519S

44. Pagmantidis V, Meplan C, van Schothorst EM, Keijer J, Hesketh JE (2008) Supplementation of healthy volunteers with nutritionally relevant amounts of selenium increases the expression of lymphocyte protein biosynthesis genes. Am J Clin Nutr 87:181189

45. Pietilñinen KH, Sysi-Aho M, Rissanen A, Sepp+ñnen-Laakso T, Yki-J+ñrvinen H, Kaprio J, Oresic M (2007) Acquired obesity is associated with changes in the serum lipidomic profile independent of genetic effects-a monozygotic twin study. PLOS ONE 2:e218

46. Reed MC, Nijhout HF, Neuhouser ML, Baird JF, Shane B, James SJ, Boynton A, Ulrich CM (2006) A mathematical model gives insights into nutritional and genetic aspects of folate-mediated one-carbon metabolism. J Nutr 136:2653-2661

47. Rein D, Schijlen E, Kooistra T, Herbers K, Verschuren L, Hall R, Sonnewald U, Bovy A, Kleemann R (2006) Transgenic flavonoid tomato intake reduces $\mathrm{C}$-reactive protein in human $\mathrm{C}$-reactive protein transgenic mice more than wild-type tomato. J Nutr 136:2331-2337

48. Ridker PM (2007) Inflammatory biomarkers and risks of myocardial infarction, stroke, diabetes, and total mortality: implications for longevity. Nutr Rev 65:S253-S259

49. Ridker PM, Hennekens CH, Buring JE, Rifai N (2000) Creactive protein and other markers of inflammation in the prediction of cardiovascular disease in women. $\mathrm{N}$ Engl $\mathrm{J}$ Med 342:836-843

50. Rocca-Serra P, Brazma A, Parkinson H, Sarkans U, Shojatalab M, Contrino S, Vilo J, Abeygunawardena N, Mukherjee G, Holloway E, Kapushesky M, Kemmeren P, Lara GG, Oezcimen A, Sansone SA (2003) ArrayExpress: a public database of gene expression data at EBI. C R Biol 326:1075-1078

51. Saal LH, Troein C, Vallon-Christersson J, Gruvberger S, Borg A, Peterson C (2002) BioArray Software Environment (BASE): a platform for comprehensive management and analysis of microarray data. Genome Biol 3:3

52. Sanderson LM, de Groot PJ, Hooiveld GJ, Koppen A, Kalkhoven E, Muller M, Kersten S (2008) Effect of synthetic dietary triglycerides: a novel research paradigm for nutrigenomics. PLoS ONE 3:e1681

53. Sansone SA, Fan T, Goodacre R, Griffin JL, Hardy NW, Kaddurah-Daouk R, Kristal BS, Lindon J, Mendes P, Morrison N, Nikolau B, Robertson D, Sumner LW, Taylor C, van der WM, van OB, Fiehn O (2007b) The metabolomics standards initiative. Nat Biotechnol 25:846-848

54. Sansone SA, Fan T, Goodacre R, Griffin JL, Hardy NW, Kaddurah-Daouk R, Kristal BS, Lindon J, Mendes P, Morrison N, Nikolau B, Robertson D, Sumner LW, Taylor C, van der WM, van OB, Fiehn O (2007a) The metabolomics standards initiative. Nat Biotechnol 25:846-848

55. Sarria B, Dainty JR, Fox TE, Fairweather-Tait SJ (2005) Estimation of iron absorption in humans using compartmental modelling. Eur J Clin Nutr 59:142-144

56. Schieffer B, Selle T, Hilfiker A, Hilfiker-Kleiner D, Grote K, Tietge UJ, Trautwein C, Luchtefeld M, Schmittkamp C, Heeneman S, Daemen MJ, Drexler H (2004) Impact of interleukin-6 on plaque development and morphology in experimental atherosclerosis. Circulation 110:3493-3500

57. Smilde AK, Jansen JJ, Hoefsloot HC, Lamers RJ, van der GJ, Timmerman ME (2005) ANOVA-simultaneous component analysis (ASCA): a new tool for analyzing designed metabolomics data. Bioinformatics 21:3043-3048

58. Tinsley FC, Taicher GZ, Heiman ML (2004) Evaluation of a quantitative magnetic resonance method for mouse whole body composition analysis. Obes Res 12:150-160

59. Turner SM, Roy S, Sul HS, Neese RA, Murphy EJ, Samandi W, Roohk DJ, Hellerstein MK (2007) Dissociation between adipose tissue fluxes and lipogenic gene expression in ob/ob mice. Am J Physiol Endocrinol Metab 292:E1101-E1109 
60. Ulrich CM, Nijhout HF, Reed MC (2006) Mathematical modeling: epidemiology meets systems biology. Cancer Epidemiol Biomarkers Prev 15:827-829

61. van den Bosch HM, De Wit NJ, Hooiveld GJ, Vermeulen H, van d, V, Houten SM, Kuipers F, Muller M, van der MR (2008) A cholesterol free, high-fat diet suppresses gene expression of cholesterol transporters in murine small intestine. Am J Physiol Gastrointest Liver Physiol

62. van Erk MJ, Blom WAM, van Ommen B, Hendriks HFJ (2006) High-protein and high-carbohydrate breakfasts differentially change the transcriptome of human blood cells. Am J Clin Nutr $84: 1233-1241$

63. van Ommen B, Stierum R (2002) Nutrigenomics: exploiting systems biology in the nutrition and health arena. Curr Opin Biotechnol 13:517-521

64. Vickers MH, Krechowec SO, Breier BH (2007) Is later obesity programmed in utero? Curr Drug Targets 8:923-934

65. Weissleder R, Moore A, Mahmood U, Bhorade R, Benveniste H, Chiocca EA, Basilion JP (2000) In vivo magnetic resonance imaging of transgene expression. Nat Med 6:351-355

66. Weissleder R, Tung CH, Mahmood U, Bogdanov A Jr (1999) In vivo imaging of tumors with protease-activated near-infrared fluorescent probes. Nat Biotechnol 17:375-378

67. Williams CM, Ordovas JM, Lairon D, Hesketh JE, Lietz G, Gibney MJ, Ommen B (2008) The challenges for molecular nutrition research 1-linking genotype to healthy nutrition. Genes Nutr 1-6-2008. Ref type: Generic

68. Wybranska I, Malczewska-Malec M, Niedbal S, Naskalski JW, Dembinska-Kiec A (2003) The TNF-alpha gene NcoI polymorphism at position -308 of the promoter influences insulin resistance, and increases serum triglycerides after postprandial lipaemia in familiar obesity. Clin Chem Lab Med 41:501-510

69. Yang M, Baranov E, Jiang P, Sun FX, Li XM, Li L, Hasegawa S, Bouvet M, Al-Tuwaijri M, Chishima T, Shimada H, Moossa AR, Penman S, Hoffman RM (2000) Whole-body optical imaging of green fluorescent protein-expressing tumors and metastases. Proc Natl Acad Sci USA 97:1206-1211

70. Yetukuri L, Ekroos K, Vidal-Puig A, Oresic M (2008) Informatics and computational strategies for the study of lipids. Mol Biosyst 4:121-127

71. Yetukuri L, Katajamaa M, Medina-Gomez G, Seppanen-Laakso T, Vidal-Puig A, Oresic M (2007) Bioinformatics strategies for lipidomics analysis: characterization of obesity related hepatic steatosis. BMC Syst Biol 1:12

72. Zeisel SH, Freake HC, Bauman DE, Bier DM, Burrin DG, German JB, Klein S, Marquis GS, Milner JA, Pelto GH, Rasmussen KM (2005) The nutritional phenotype in the age of metabolomics. J Nutr 135:1613-1616 